\title{
PRINSIP-PRINSIP FILSAFAT PENDIDIKAN KRISTEN
}

\author{
Tety \& Soeparwata Wiraatmadja \\ Sekolah Tinggi Teologi Sangkakala \\ Getasan, Kab. Semarang \\ E-mail: pelangikasih14@gmail.com
}

\begin{abstract}
Tety and Soeparwata Wiraatmadja, The Philosophy Principles of Christian Educating. This paper discusses the principles of the philosophy of Christian education. The writer describes in the paper some important issues related to the principles of the philosophy of Christian education including the review of the Christian education of theological and philosophical aspects, then epistemology and axiology, the philosophy and purpose of Christian education. The final part of this paper the author describes some of the principles of the philosophy of Christian education.
\end{abstract}

Keyword: Philosophy, Christian educating, theological aspects.

ABSTRAK: Tety dan Soeparwata Wiraatmadja, Prinsip-Prinsip Filsafat Pendidikan Kristen. Makalah ini membahas tentang prinsip-prinsip filsafat pendidikan Kristen. Penulis menguraikan dalam makalah beberapa hal penting terkait prinsip-prinsip filsafat pendidikan Kristen diantaranya adalah tinjauan terhadap pendidikan Kristen dari aspek teologis dan filsafatnya, lalu epistemologi dan aksiologi, filsafat dan tujuan pendidikan Kristen. Bagian akhir dari makalah ini penulis menguraikan beberapa prinsip filsafat pendidikan Kristen.

Kata kunci: Filsafat, pendidikan Kristen, aspek teologis.

\section{PENDAHULUAN}

Pendidikan merupakan usaha yang dilakukan untuk menolong seseorang mengalami perubahan. Pendidikan juga memainkan peranan penting dalam sejarah kehidupan manusia. Demikian pula pendidikan Kristen berperan penting dalam sejarah kekristenan. Praktik pendidikan sangat dipengaruhi oleh prinsip filsafat pendidikan, termasuk juga praktik pendidikan Kristen harus dijalankan berdasarkan prinsip filsafat pendidikan Kristen. Kurang tepatnya pendidikan Kristen dapat dilatarbelakangi kurang difahaminya prinsip filsafat pendidikan Kristen. Filsafat pendidikan Kristen dapat menjadi rel pelaksanaan pendidikan. Pada dasarnya terdapat prinsipprinsip penting dalam pendidikan Kristen dan prinsip-prinsip tersebut perlu diuraikan sehingga dapat memberi menjawab pertanyaan "apa yang menjadi prinsip-prinsip filsafat pendidikan Kristen?"

Melalui makalah ini, penulis menguraikan prinsip filsafat pendidikan Kristen dan menguraikan beberapa hal penting terkait prinsip-prinsip filsafat pendidikan Kristen diantaranya adalah tinjauan ter- hadap pendidikan Kristen dari aspek teologis dan filsafatnya, lalu epistemologi dan aksiologi, filsafat dan tujuan pendidikan Kristen, serta prinsip-prinsip filsafat pendidikan Kristen.

\section{METODE}

Jenis penelitian dalam penelitian ini adalah penelitian pustaka. Penulis melakukan kajian terhadap sumber-sumber pustaka dan menguraikannya dalam sebuah kerangka uraian sehingga lebih mudah dipahami. Penulis menggunakan sumber-sumber acuan yang tahun terbitnya telah lama, tetapi masih dianggap menjadi sumber utama. Selain itu, penulis menggunakan beberapa sumber tambahan dari bukubuku yang membahas perkembangan filsafat pendidikan pada masa kini. Sumber-sumber pustaka yang digunakan dalam kajian ini adalah karya (1) M.J. Langeveld, Beknopte Theoritische Paedagogiek. Bandung: Jemmars, 1980; (2) F. Danuwinanta, ed., Karya Lengkap Driyarkara: Esai-Esai Filsafat Pe- 
mikir yang Terlibat Penuh dalam Perjuangan Bang-

sanya. Jakarta: Gramedia Pustaka Utama, 2006.

\section{PENDIDIKAN KRISTEN DI TINJAU DARI ASPEK TEOLOGIS DAN FILSAFATNYA}

\section{Pendidikan}

Pendidikan adalah usaha yang dilakukan orang dewasa untuk menolong seorang anak yang belum dewasa, membimbing, menuntun dan mengarahkannya untuk mencapai kedewasaan atau kemandirian. Sementara ilmu pendidikan adalah ilmu bersifat teoretis, berdiri sendiri, murni, mengacu kepada seluruh gejala pendidikan kemudian dipegang dan diuraikan dengan menarik sepenuhnya keluar dari gejala hidup yang ada, meninjaunya sebagai sasaran khusus, menjelaskannya dan berusaha memahami dan mencari maksudnya. M.J Langeniveld menyatakan bahwa pendidikan atau pedagogik merupakan kegiatan membimbing anak manusia menuju kepada kedewasaan dan kemandirian cirinya adalah: individualitas, personalitas, sosialitas, dan moralitas. ${ }^{1}$ Sementara itu, Driyarkara merumuskan pendidikan sebagai usaha memanusiakan manusia dan membudayakannya. ${ }^{2}$ Jadi ilmu pendidikan membicarakan masalah-masalah pendidikan baik teoretis maupun praktis. Agar dapat dipertanggungjawabkan secara ilmiah, maka pendidikan perlu landasan kefilsafatan. Melalui filsafat dapat dilahirkan pemikiranpemikiran teoritis di dalam pendidikan dan pelaksanaannya. Dengan demikian filsafat pendidikan sangat erat berkaitan dengan pendidikan dan mendukung pelaksanaannya agar kokoh dan terarah.

\section{Pendidikan dalam Alkitab}

Di dalam Ulangan 6:6-9 dinyatakan:

\footnotetext{
${ }^{1}$ M.J. Langeveld, Beknopte Theoritische Paedagogiek, terj.:Simajuntak, (Bandung: Jemmars, 1980).

${ }^{2}$ F. Danuwinanta, ed., Karya Lengkap Driyarkara: Esai-Esai Filsafat Pemikir yang Terlibat Penuh dalam Perjuangan Bangsanya (Jakarta: Gramedia Pustaka Utama, 2006), 415.
}

apa kuperintahkan kepadamu pada hari ini haruslah engkau perhatikan. Haruslah engkau mengajarnya berulang-ulang kepada anak-anakmu dan membicarakannya apabila engkau duduk di rumahmu, apabila engkau sedang dalam perjalanan, apabila engkau berbaring, dan apabila engkau bangun. Haruslah juga engkau mengikatnya sebagai tanda pada tanganmu dan haruslah itu menjadi lambang di dahimu, dan haruslah engkau menuliskannya pada tiang pintu rumahmu dan pada gerbangmu.

Demikian pula dalam Amsal 29:17 dinyatakan: "didiklah anakmu, maka ia akan memberikan ketentraman kepadamu, dan mendatangkan sukacita padamu." Allah memerintahkan kepada orang Israel, khususnya kedua orang tua mempunyai anak agar mereka mengajari dan mendidik anak mereka secara berulang-ulang, mengajari anak mereka takut akan TUHAN, mengajari anak mereka takut akan Allah. Kenapa harus diajarkan berulang-ulang? Supaya pendidikan pertama itu kuat.

Matius 7:28-29 “... setelah Yesus mengakhiri perkataan ini, takjublah orang banyak itu mendengar pengajarannya, sebab ia mengajar mereka sebagai orang berkuasa, tidak seperti ahli-ahli taurat mereka." Tuhan Yesus memberikan contoh bagaimana cara mengajarkan. Ia mengajarkan dengan keteladanan, Ia mengajar dengan hati, Ia mengajar dengan penuh kuasa. Yesus memberitakan kerajaan sorga sudah dekat. Amanat Agung Tuhan Yesus dalam Matius 28:19-20 memerintahkan agar muridmurid-Nya, dalam hal ini termasuk juga orang Kristen masa kini, untuk menjadikan semua bangsa sebagai murid-Nya.

Dalam paparan ini didapat bahwa pendidikan merupakan pelita menyala membawa dan menuntun manusia untuk kembali ke rencana Allah semula. Dalam hal ini, pendidikan dipakai untuk menuntun manusia menuju kebenaran yaitu Yesus Kristus. Pelita hanyalah sebatas alat. Apabila tidak ada sumber cahaya membuatnya menyala, maka ia tidak akan berguna. Ada pun sumber tenaga itu adalah Kristus sendiri direfleksikan melalui Alkitab. Dengan demikian dapat dikatakan bahwa menjadi inti dari pusat 
Kristen adalah Yesus "kembali kerencana Allah." Berarti membawa, manusia melalui teladan pribadi Yesus Kristus.

Mazmur 119:105 menyatakan: "Firman-Mu itu pelita bagi kakiku, dan terang bagi jalanku". Ini sejajar dengan Timotius 3:16 "segala tulisan yang diilhamkan Allah memang bermanfaat untuk mengajar, untuk menyatakan kesalahan, dan untuk mendidik orang dalam kebenaran, jadi melalui pendidikan berdasarkan firman Tuhan-lah mampu menuntun manusia menjadi pribadi yang berkenan dihadapan Allah dengan meneladani pribadi Yesus Kristus".

Dari paparan tersebut jelas ada landasan yang kokoh secara teologis dari pendidikan yang dianut Alkitab.

\section{Filsafat Pendidikan}

Filsafat pendidikan adalah ilmu pendidikan bersendikan filsafat atau filsafat yang diterapkan dalam pemikiran dan pemecahan masalah pendidikan. John Dewey menyatakan bahwa: "philosophy may even be difined as the general theory of education." Ada hubungan timbal balik antara filsafat dan pendidikan. Dapat juga merupakan suatu cara menjawab dan memecahkan persoalan-persoalan yang bersifat filosofis dan memerlukan jawaban secara filosofis juga. Isi kandungan filsafatnya mendasari berbagai pemikiran mengenai pendidikan yaitu: MetaphysikaOntologi, Epistemologi, dan Aksiologi.

Alkitab adalah praanggapan atau titik tolak pemikiran filsafat Kristen sekaligus filsafat pendidikan Kristen. Dari akar teologis dibangunlah konsep filsafat ini. Bagi seorang Kristen Allah adalah pencipta alam semesta. Manusia diciptakan segambar dengan Allah. Kendati demikian manusia telah jatuh ke dalam dosa terseret oleh pemberontakan kepada Allah. Hanya oleh penebusan Yesus Kristus

3“John Dewey (1859-1952) - Experience and Reflective Thinking, Learning, School and Life, Democracy and Education" http://education.stateuniversity. com/pages/1914/Dewey-John-1859-1952.html. Diakses pada 7 April 2016. sang cahaya terang itu manusia diselamatkan. Alam semesta ada dikendalikan hukum Allah diciptakan oleh Allah, Kristuslah cahaya keselamatan yang meletakan dasar kerajaan Allah dan menolong manusia kembali kepadanya dan menyempurnakannya.

\section{EPISTEMOLOGI}

Epistemologi berkaitan dengan pengetahuan dan kebenaran, hal apa yang kita ketahui dan cara kita dapat mengetahuinya. Epistemologi menjawab tentang kebenaran dan pengetahuan. Epistemologi adalah cabang dari filsafat yang mempelajari sifat, sumber dan validitas dari pengetahuan. Yesus adalah terang dan jalan kebenaran. Sesuai dengan iman yang kita miliki. Satu hal paling sesuai untuk epistemologi adalah bahwa Yesus merupakan terang dan jalan kebenaran. Kehidupan kekal hanya bisa kita dapatkan dari Dia. Dengan kata lain, tidak ada jalan menuju kekekalan bila tidak melalui Dia. Bagaiman kita membuktikan hal ini? Ada dua cara untuk menentukan epistemologi, yaitu dengan menggunakan panca indera dan kesaksian. Dan untuk membuktikan hal ini sudah banyak kesaksian yang diberikan mengenai hal ini secara turun-temurun. Tidak ada kebenaran diluar kerangka metafisika Allah. Semua kebenaran yang ada di dunia ini tidak ada yag diluar Allah, semuanya juga tertulis dalam Alkitab, semua kebenaran tersebut tercakup dalam Alkitab.

\section{AKSIOLOGI}

Aspek aksiologi merupakan aspek filsafat yang berkaitan dengan nilai tertinggi, dan bermakna. Aspek ini terbagi dalam nilai etika dan estetika. Etika merupakan studi tentang nilai-nilai moral dan perilaku. Aksiologi menjawab pertanyaan "apa itu kebenaran, apa yang seharusnya dilakukan seseorang pada saat situasi seperti ini?". Estetika adalah studi dari nilai-nilai umum, prinsip yang mengatur penciptaan dan penghargaan terhadap keindahan dan seni. Estetika menjawab pertanyaan "apa itu keindahan, apa yang indah dari seni tersebut?". 
Pada awalnya manusia diciptakan segambar dan serupa dengan Allah, dan dalam eksistensinya manusia diciptakan sebagai makhluk yang memuliakan Allah. Akan tetapi semua ini berubah sejak kejatuhan manusia kedalam dosa. Manusia tidak dapat menjalankan fungsi dan tugasnya seperti sedia kala. Hubungan manusia dengan Tuhan pun terputus. Sebagai mahluk yang religius, manusia terus mencari keberadaan Tuhan itu sendiri. Hal ini dapat kita lihat dalam kehidupan dan kebudayaan manusia khususnya di Asia yang masih banyak melakukan pemujaan kepada berhala. Sayangnya, usaha manusia ini tidak akan pernah berhasil dalam menemukan Tuhan. Pertemuan ini hanya akan terjadi apabila Tuhan sendiri yang berinisiatif. Kedatangan Kristus ke dalam dunialah yang menjadi titik balik hubungan manusia dengan Allah.

Melalui kematian Kristus di kayu salib, Allah menunjukan kasih dan keadilan yang sesungguhnya. Hubungan manusia didamaikan dengan Allah, dan dilayakan kembali untuk datang kepada Allah, bahkan disebut anak-anak Allah. Ia menegaskan bahwa Dialah Allah yang penuh kasih dan adil sehingga Dia harus mendisiplin umat-Nya. Dalam salib Kristus nilai-nilai moral yang sesungguhnya terpresentasikan. Bahkan melalui salib Kristus manusia diperdamaikan dengan Allah dan status manusia pun menjadi baru. Manusia menjadi anak-anak Allah yang menjadi terang dan membawa energi dari terang itu sendiri yaitu cahaya, dimana cahaya itu sebenarnya mencerminkan siapakah kita ini? Kita adalah anak-anak Allah yan telah diselamatkan, sehingga kita harus menjadi surat terbuka yang dapat dibaca setiap orang. Nilai estetika disini bukan menekankan kepada keindahan alam namun pada keindahan manusia itu sendiri, karena dicipta segambar dan serupa dengan Kristus. Setiap manusia memiliki keindahan tersendiri, antara satu dengan yang lain pasti memiliki perbedaan, baik wajah maupun karakter. Dengan begitu banyaknya populasi manusia di dunia ini, kita tentu bisa membayangkan betapa menakjubkan ciptaan Allah yang bernama manusia ini. Akan tetapi, karena keberdosaan kita keindahan yang terpancar bukan lagi dari dalam jiwa kita. Kejatuhan manusia membuat manusia tidak lagi mencermikan dan mempresentasikan Allah yang semula. Seperti halnya dengan pelita, pelita tidak akan memancarkan cahayanya apabila tidak memiliki sumber cahaya itu sendiri. Dan ia hanya akan menjadi pelita yang pasif dan tidak akan menjadi pelita bila tidak menjalankan fungsinya.

Pendidikan adalah pelita yang harus terus menyala untuk menerangi dan menuntun manusiamanusia berharga yang Allah ciptakan kembali kepada-Nya. Namun, sebagai pelaku pendidikan kita harus terus diperbaharui oleh Roh Kudus, yaitu dengan membaca firman-Nya dan terus membangun hubungan pribadi dengan Tuhan.

\section{FILSAFAT DAN TUJUAN PENDIDIKAN KRISTEN}

Pendidikan Kristen adalah pendidikan yang berpusat pada Allah, suatu implikasi dan interpretasi kasih Allah. Pendidikan Kristen menggunakan filsafat teistis yang berlandaskan kebenaran firman Tuhan yang jelas berbeda dengan filsafat pendidikan Sekuler. ${ }^{4}$ Beth E. Brown sebagaimana dikutip oleh Alfius Areng Mutak berkata Pendidikan Kristen adalah suatu interaksi dengan kebenaran yang berimplikasi pada hidup yang dipimpin dan dikuasai oleh Roh Kudus, yang menghasilkan perubahan dalam hidup para anak didik; perubahan yang menjadikannya serupa dengan Kristus. ${ }^{5}$ Adapun tujuan pendidikan Kristen menurut Gordon Brown adalah berhubungan dengan tujuan hidup orang Kristen bagi Tuhan dan kemuliaan-Nya. Pendidikan dipandang sebagai sarana yang dipergunakan oleh Roh Kudus untuk membawa murid kepada persekutuan dengan Allah, bagi hidup dalam kekekalan. Pendidikan

${ }^{4}$ Louis Berkhof dan Cornelius Van Til, Foundation Christian Education, terjemahan, cetakan ketiga, (Jakarta: Momentum, 2010), 15

${ }^{5}$ Alfius Areng Mutak, "Gereja Dan Pendidikan Kristen”, Jurnal Theologia Aletheia, Volume 7, Nomor 12 (Maret 2005), 14. 
Kristen diperuntukkan pada pengembangan pemikiran dalam perspektif Kristen dan untuk melatih mereka dalam kehidupan yang taat sehingga mereka dapat memenuhi tujuan Tuhan bagi keseluruhan hidup.

Douglos Wilson memperjelas tujuan pendidikan Kristen, yang pada dasarnya adalah suatu proses yang memfasilitasi pemulihan gambar dan rupa Allah yang telah rusak karena keberadaan dosa manusia, menuju kedewasaan sejati, sehingga anak dapat memenuhi mandat ciptaan-Nya dalam ketaatan kepada firman Allah. Pendidikan merupakan tanggung jawab setiap orang Kristen sebagai umat perjanjian Allah. Dalam memfasilitasi pemulihan gambar dan rupa Allah, Gordon Brown menguraikan empat keharusan yang perlu dilakukan dalam proses pendidikan Kristen.

\section{Belajar akan pengetahuan dan kebenaran Tuhan}

Murid harus diajarkan bahwa Alkitab adalah sumber hikmat dan pengetahuan, petunjuk bagi kehidupan, sumber keselamatan, doktrin tentang manusia, keselamatan dan Tuhan. Mengajarkan kebenaran tentang tingkah laku dan keberadaan manusia.

\section{Respon terhadap Tuhan dan kebenaran-Nya}

Murid dituntun pada keselamatan melalui iman kepada Tuhan Yesus Kristus. Respon kepadaNya menuntut komitmen dengan berserah pada kasih Tuhan dan bersedia melayani-Nya. Murid dituntun untuk menghargai kebenaran Tuhan yang terkandung dalam firman Tuhan dan dalam realitas ciptaan-Nya.

\section{Hidup Berdamai Dengan Tuhan dan Kebenaran- Nya}

Murid diajarkan taat kepada perintah Tuhan untuk hidup berkenan kepada-Nya, hidup dalam keluarga Tuhan, komunitas dan Negara. Pendidik mengajarkan murid untuk menghargai alam ciptaan Tuhan dan hidup berdasarkan hukum-hukum dan prinsip-prinsip kebenaran dalam hubungan manusia.

\section{Peran pendidikan menyatakan kebenaran-Nya}

Pendidik memberi pengaruh kepada sesama dengan pengetahuan dan kebenaran Tuhan. Pendidik melatih murid untuk mengkomunikasikan arti lisan secara efektif untuk orang lain serta berpartisipasi dalam gereja dalam arti luas dalam penginjilan dan pemuridan. Mengajarkan murid dalam pandangan yang realistis dan pespektif Alkitab.

\section{PRINSIP-PRINSIP FILSAFAT PENDIDIKAN KRISTEN}

Dalam bagian ini penulis menguraikan prinsip-prinsip filsafat pendidikan Kristen sebagai berikut (1) Allah-lah sumber segala sesuatu. Allah adalah pencipta alam semesta. Jadi filsafat pendidikan Kristen adalah Teistis yang berakar pada kebenaran firman Tuhan; (2) Manusia diciptakan segambar dengan Allah. Namun manusia jatuh ke dalam dosa, kendati demikian Tuhan memulihkan kembali sebagai pribadi yang utuh. Dengan demikian Filsafat Pendidikan Kristen memandang bahwa manusia dapat dikembalikan tubuh, jiwa dan rohnya oleh pembenaran Kristus sebagai kebenaran Kristen; (3) Pendidik adalah roh, jiwa dan tubuhnya. Hanya oleh Roh Kudus manusia dapat memancarkan cahaya terang Kristus. Itulah sebabnya Filsafat Pendidikan Kristen berusaha menunjukkan ke arah pembaharuan hidup yang sesuai kembali dengan kemuliaan Allah; (4) Alam semesta adalah ciptaan Tuhan. Filsafat pendidikan kristen memandang alam semesta adalah ciptaan Allah yang tunduk kepada Allah sebagai sarana kemuliaan-Nya; (5) Yang Berpusat kepada untuk dikembangkan sesuai dengan kehendak Allah. Filsafat Pendidikan Kristen tidak sekadar menuju pemulihan pribadi manusia, tetapi juga kasih, keadilan dan kesejahteraan umat dan seluruh alam semesta.

\section{KESIMPULAN}

Pendidikan merupakan sebuah proses yang harus dilaksanakan untuk mencapai sebuah tujuan. Dalam Perjanjian Lama dan Perjanjian Baru tersirat 
beberapa ayat yang secara tidak langsung menuju kepada pendidikan di antaranya Ulangan 6:6-9, Amsal 29:17 dan Matius 28:29. Filsafat pendidikan menjadi akar dari pendidikan yang berfungsi sebagai analisa persoalan dan pemecahan masalah. Di dalam filsafat pendidikan Kristen segala persoalan ada penyelesaian, yang runtut dan di analisa secara rinci.

Alkitab menjadi pusat pendidikan Kristen, yang memberi banyak pelajaran berharga mengenai pengalaman bersama dengan Tuhan. Adapun bahasan filsafat pendidikan meliputi epistemologi dan aksiologi. Filsafat dan tujuan pendidikan Kristen membahas mengenai proses belajar akan kebenaran Tuhan, serta respon terhadap Tuhan dan kebenaranNya yang dibuktikan dengan berdamai dengan sesama manusia dan berdamai dengan Tuhan.

Filsafat pendidikan menjadi bagian yang penting, karena induk dari segala ilmu pengetahuan.

\section{DAFTAR RUJUKAN}

"John Dewey (1859-1952) - Experience and Reflective Thinking, Learning, School and Life, Democracy and Education" http://education. stateuniversity.com/pages/1914/Dewey-John1859-1952.html. Diakses pada 7 April 2016.

Berkhof, Louis dan Cornelius Van Til, Foundation Christian Education, terjemahan, cetakan ketiga. Jakarta: Momentum, 2010.
Filsafat harus memainkan perannya sebagai pendorong, pembebas dan pendobrak. Oleh karena itu, filsafat sangat berguna dalam segala bidang kehidupan, secara khusus pendidikan Kristen. Selain dari pada itu ada prinsip-prinsip filsafat pendidikan Kristen meliputi Allah sumber segala sesuatu, manusia diciptakan segambar dan serupa dengan Allah, pemulihan gambar dan rupa Allah dalam diri manusia, alam semesta adalah ciptaan Tuhan yang dikembangkan sesuai dengan kehendak Allah. Filsafat pendidikan Kristen tidak hanya mengajarkan kebenaran, melainkan mendorong manusia kepada pembaharuan budi dan mempraktekkan setiap kebenaran ke dalam kehidupan secara nyata. Hal ini membuktikan filsafat pendidikan Kristen bukan sekedar teori melainkan tindakan praktis, yang dapat di lihat dan rasakan sumber kebenarannya.

Danuwinanta, F. ed., Karya Lengkap Driyarkara: Esai-Esai Filsafat Pemikir yang Terlibat Penuh dalam Perjuangan Bangsanya. Jakarta: Gramedia Pustaka Utama, 2006.

Langeveld, M.J. Beknopte Theoritische Paedagogiek, terj.:Simajuntak. Bandung: Jemmars, 1980.

Mutak, Alfius Areng. "Gereja Dan Pendidikan Kristen", Jurnal Theologia Aletheia, Volume 7 Nomor 12 (Maret 2005). 